\title{
Quality of Clinical Notes: Lesson Learned from Elective Surgery Patients Admitted at University Teaching Hospital
}

\author{
Jay Narayan Shah, ${ }^{1}$ Shantbir Maharjan, ${ }^{1}$ Shailendra Shah ${ }^{1}$ \\ 1Department of Surgery, Patan Hospital, Patan Academy of Health Sciences, Lalitpur, Nepal.
}

\section{ABSTRACT}

\begin{abstract}
Background: Informative relevant documentation regarding course of treatment minimizes errors, provides data for evidence based practice and legality. However, the clinical notes are often inadequate. This study aims to analyse quality of structured clinical notes in surgical patients.

Methods: This cross sectional study from Oct 1, 2015 in department of surgery included 100 clinical notes randomly selected by lottery. The entries in notes were predefined. There were 29 general entries (nine for identification, eleven for admission details, eight for treatment progress, and one for handwriting). Three additional entries were for discharge patients. The decision for entries was based on consensus meeting in surgery department. Microsoft excel was used for data entry and descriptive analysis.

Results: There were 100 clinical notes analysed, 62 non-discharge and 38 discharge patients. Four (out of 62) nondischarge had all 29 entries documented. Two (out of 38) in discharge had all 32 entries documented. The "date of entries, clinician name and designation” were mentioned in $12 \%, 13 \%$ and $10 \%$, respectively. The progress on diet was recorded in 53\%, investigations in $72 \%$ and intervention details in $73 \%$. Handwriting was difficult to read in $21 \%$. In 13 (out of 100) the identification information was incomplete. Discharge lacked details of home advice in $11 \%$.

Conclusions: The quality of clinical note of elective surgery patients needs improvement on documentation in all domains of identification, admission, progress and discharge.
\end{abstract}

Keywords: Admission discharge information; elective surgery; quality of clinical notes; tertiary care teaching hospital.

\section{INTRODUCTION}

Patient care is evolving dynamic process. Comprehensive care involves health professionals, family and friends of patients, community, socially acceptable norms and evidence based approach for optimum outcome of patients. Informative, relevant clinical note is important for better and continued care. Documentation minimizes possible errors in the course of care, provides basis for further research and basis of evidence when there is medico-legal issues. Individual health professional has the responsibility to maintain optimum patient records. Standardized and structured clinical note is essential to improve doctors' performance and outcome to achieve good health care delivery. ${ }^{1,2}$

General knowledge and skills taught in medical schools to document history, examination, diagnosis, treatment and follow-up is the basis for optimum patient care.
However, information documented in the clinical notes often varies widely and are inadequate, for examplethe details of important information, such as important physical findings, medication or investigation, can lead to adverse events and poor clinical outcome. ${ }^{3,4}$

Locally and in the region, we lack agreed upon essential format of structured clinical note. Periodic audit is crucial for critical appraisal and improvements of the quality of documents. We prospectively analyzed the quality of clinical notes of admitted surgical patients for completeness of information and need of improvements. This study aims to provide information on use of structured clinical notes in surgical patients which could be further modified to develop a guideline on quality of clinical notes and can be modified for use in disciplines other than surgery.

Correspondence: Dr Jay Narayan Shah, Department of Surgery, Patan Academy of Health Sciences, Lalitpur, Nepal. Email: drjaywufei@hotmail.com, drjaywufei@ gmail.com, Phone: 9779851040139. 


\section{METHODS}

This was a cross sectional study at department of surgery from Oct 1, 2015. We randomly selected 100 patients. Ten intern doctors rotating in surgery ward were briefed to 'look into' the patients' case notes for the completeness and accuracy of pre-defined entries. Ten case notes of admitted surgery patients were randomly selected by simple lottery on working days (Sun, Mon, Tue, Thu, and Friday). The bed numbers of all admitted patients were written on separate pieces of paper, folded and put in a large envelop. Ten folded pieces were drawn randomly, and then put into another envelope. Ten intern doctors each drew one number to review the respective patient chart. This process was repeated for ten days till we had 100 samples. On subsequent days if the number drawn were that of previously drawn patients, then another draw was taken.

The entries in clinical notes were predefined for completeness necessary for quality care. There were 29 general entries and additional three for discharge patients. The consensus decision for relevancy of entries (variables) was based on discussion in the surgery department meeting attended by faculties, residents, and intern doctors. Each entry was given score of one (present) or zero (absent). Thus, a maximum score of 29 was necessary for completeness of note and additional three, i.e. 32 for the discharge patients. Legibility of entries was based on whether hand writing was readable (one) or not readable (zero). Microsoft Excel was used for data entry and descriptive analysis. Study was approved by institutional review committee, IRC-PAHS.

\section{RESULTS}

Out of 100 clinical notes studied, 62 were non discharge and 38 discharge patients. Four $(6.5 \%$ of 62$)$ in non discharge had all 29 entries, and in two (5.3\% of 38) discharge patients had all 32 entries noted. In 13 (13\% out of 100), the information for identification of patient was incomplete. The 'date, clinician name and designation' was noted in $12 \%, 13 \%$ and $10 \%$, respectively. Drug and social history was detailed in $30 \%$ and $23 \%$, respectively. In daily progress notes, the details of changes in diet were noted in $53 \%$, investigations in $72 \%$ and intervention in $73 \%$. Handwriting was difficult to read in $21 \%$. The clinical notes of the patients who were being discharged lacked the information on home advice about medicine, diet, physical activity and dressing in 11\%, (Table 1).

\section{DISCUSSION}

Our study showed there was serious lacking in documentation in clinical notes of elective surgery patients. Only four out of 62 (6.5\%) non-discharge patients had complete information on all the 29 general entries. Among 38 discharge patients, only two (5.3\%) had all 32 entries. Furthermore, the crucial information on 'identification of patients' were incomplete in 13 (13\% patients). Similarly inadequate documentation has been reported as common occurrence in clinical practice that may compromise quality of care, cause adverse incidents and lead to poor outcome. ${ }^{3,4}$

When the individual sections of the score were analyzed separately, the general information for identification of patients and doctors ( 9 entries) that are crucial and must have information were incomplete with missing data in $13 \%$ (13 out of 100). The deficiency was in details of contact number and address of the patients. For identification of doctors, the consensus decision on "every entry should be signed, every note should be dated and every entry should have clinician designation" had lowest score of $17 \%, 13 \%$ and $10 \%$, respectively. Lack of these entries could be the issue of not being responsible when there is need to 'identify' the clinician who is taking care of and is responsible for the management of patients, for example, in circumstances of dispute about the care and medico-legal issues. Information to accurately identify patient 'Identification data- name, age, sex, hospital number, date, contact number, addresses' were noted in $87 \%$ only. This could lead to unwanted consequences in time of urgency when the patient's family needs to be contacted. Despite recommendations and advice from Royal College of Surgeons and Physicians, the NCEPOD (National Confidential Enquiry into Patient Outcome and Death), the study found that the standard of initial assessment was unacceptable in $7.1 \% .^{5}$ This is also interesting to note from published evidence that doctors who record more data are likely to detect adverse events. ${ }^{6}$

In present study, the initial clinical information on admission was also lacking. The details of social history about duration and quantity of alcohol and tobacco (smoking or chewable) were mentioned in only $23 \%$. The crucial information to initiate prompt treatment, for e.g. type of admission (emergency or elective) and chief complaint was mentioned in $87 \%$ only, previous history of tuberculosis, diabetes, and hypertension was mentioned in $69 \%$ only. More serious lacking was in details of initial examination, present in $81 \%$, initial plan of treatment in $79 \%$ and progress note with specific plan of treatment in $85 \%$ only. Even the working diagnosis was present only in $88 \%$. These details are important and further influence the course of treatment and final outcome. For any modification of diagnosis or treatment there must be a 
Table 1. Documentation of entries required for quality clinical notes in elective surgery patients $(n=100)$ admitted in a tertiary care university teaching hospital.

Entry categories for Details of entries for quality clinical notes quality clinical notes

(score-- present 1 , absent 0)

\begin{tabular}{|c|c|}
\hline $\begin{array}{l}\text { Non- } \\
\text { discharge } \\
(n=62)\end{array}$ & $\begin{array}{l}\text { Discharge } \\
\text { patients } \\
(n=38)\end{array}$ \\
\hline 87 & \\
\hline 83 & \\
\hline 82 & \\
\hline 12 & \\
\hline 51 & \\
\hline 17 & \\
\hline 13 & \\
\hline 10 & \\
\hline 81 & \\
\hline
\end{tabular}

$\begin{array}{lllll}\text { B. } & \text { B1. On } & 1 & \text { Type of admission- emergency, elective } & 87\end{array}$

$\begin{array}{llll}\text { Clinical admission } 2 & \text { Presenting/chief complaint } & 87\end{array}$

content 3 History of presenting/chief complaint 75

$\begin{array}{lll}\text { entries) } & 4 & \text { Previoushistory(no/yes- details of TB, HTN, DM, other/ }\end{array}$ surgery)

$5 \quad$ Allergies/warnings- no, if yes details 60

6 Family history- married, unmarried, divorced, menstruation 50 and pregnancy

7 Drug history- no, if yes details of type, duration, dose 30

8 Social history- duration, quantity of alcohol, tobacco 23 (smoke/ chew)

9 Details of initial examination $\quad 81$

10 Working diagnosis $\quad 88$

11 Plan of treatment/investigations $\quad 79$

B2. Daily 1 Relevant complaint 91

progress 2 Relevant clinical findings as per specific disease/surgery 90

notes (8 3 Plan of treatment- specify (in progress sheet/dr order/ 85

entries) drug sheet)

4 Drugs - name, dose, route, duration 72

$5 \quad$ Iv fluid - name, dose, route, duration 64

6 Oral diet- sips, liquid/soft/normal 53

\begin{tabular}{ll}
7 & Investigations \\
\hline
\end{tabular}

8 Intervention $\quad 73$

$\begin{array}{llll}\text { C. Legibility- } & 1 & \text { Readable } & 79\end{array}$

handwriting

$\begin{array}{lllll}\text { D. Discharge plan, } & 1 & \text { Discharge diagnosis, if different from admission clarification } & - & 98 \\ \text { when the 'discharge' } & 2 & \text { Home advise- medicine, diet, physical activity, dressing etc } & - & 89 \\ \begin{array}{l}\text { was mentioned in } \\ \text { Dr's order (3 entries) }\end{array} & 3 & \text { Follow-up when and where } & - & 97\end{array}$


logical explanation as why earlier diagnosis or treatment requires change. Also, there must be documentation to show clearly that modified management is working. Approximately half of the clinical notes (53\%) did not have details of progression of oral diet, sips, liquid or normal. This documentation is necessary to omit unnecessary intravenous fluid in patient who can tolerate oral diet. ${ }^{7}$ Similarly, the details of drugs and antibiotics to justify their use was noted in $72 \%$ only, where as in clinical practice the logical explanation is necessary to justify the necessity of use of antibiotics. ${ }^{8}$

In this study, we noticed $21 \%$ of clinical notes were difficult to comprehend due to difficult to read handwriting. Doctors are famous for 'scribble' with difficult to read handwritings which at times create blunders. Readable writing, preferably with identification of persons who makes entries of relevance and accuracy serves as evidence in case of litigation. ${ }^{9}$

The discharge advice of medicine, diet, physical activities, dressing etc were lacking in $11 \%$. The home advice is important and a matter of concern for patients and family after leaving hospital. It affects the compliance and overall outcome after surgery. The detail instruction, preferably in written form provides ease of mind to patients and family, more so in our society where there is lack of community nurses and family physicians. ${ }^{10}$

This study shows our clinical notes have problems with documentation, are inadequate and lacks necessary information to be recorded in the patient chart during the course of patients care and need to be improved with detail entries. The teaching in medical schools to systematically document history, physical examination, relevant investigations and treatment process for the care of patients, and use of structured standardised clerking, were not adhered to in our daily practice as found in other studies. ${ }^{11,12}$ Standardizing entries in clinical notes during the course of care is important for consistency. Structured, agreed upon entries improves documentation. The CRABEL score has been shown to be a useful, reproducible and easy-to-perform objective assessment of the quality of medical record keeping. Repeated audit cycles have ensured that case-note quality remains a high priority and have also led to the development of standardized admission documentation for measurable improvement in record keeping. . $^{2113-15}$

Our findings suggest that there is need of reinforcement to knowledge and skills learned in medical school in regard to documentation of clinical history, and further management of patients. Standardized clinical note of relevance requires input from all health care personnel, doctors, nurses and paramedical staff who are directly involved in overall care of patient. Furthermore, the holistic care involves patients, family, management, community and society as a whole because medicine is more than just facts and figures of science and includes much bigger circle outside of health professional and patients. Good clinical note is the basis of quality patient care. Our study shows adequate and relevant information in clinical notes needs to be improved. Implementation of structured clinical note with periodic audit for revisit and reflection will help maintain consistency and improve quality of care for patients.

\section{CONCLUSIONS}

Quality of clinical notes in admitted surgery patients need improvement both in required number of entries and details in all the domains of general information for identification of patients and doctors, initial clinical details on admission and progress as well as discharge advice.

\section{ACKNOWLEDGEMENTS}

We are thankful for the intern doctors- Aaradhana Adhikari, Bibek Raj Poudel, Dhanmaya Ghartimagar, Kailash Chhetri, Namita Shakya, Raju Gurung, Ramhari Regmi, Samriddha Thapa, Sudeep Chapagain who helped in data collection to complete this work.

\section{REFERENCES}

1. Mann R, Williams J.Standards in medical record keeping. Clin Med. 2003;3(4):329-32. [PubMed]

2. Ho MY, Anderson AR, Nijjar A, Thomas C, Goenka A, Hossain J, et al. Use of the CRABEL Score for improving surgical case-note quality. Ann R Coll Surg Engl. 2005;87(6):454-7. [PubMed]

3. Zegers M, de Bruijne MC, Spreeuwenberg P, Wagner C, Groenewegen PP, vander Wal G. Quality of patient record keeping: an indicator of the quality of care? BMJ QualSaf. 2011;20(4):314-8.[PubMed]

4. Audit Commission. Improving data quality in the NHS: Executive Summary. London: Audit Commission; 2012. [Full Article]

5. NCEPOD. Emergency admissions: a journey in the right direction? London: A report of the National Confidential Enquiry into Patient Outcome and Death; 2007. [Full Ar$\underline{\text { ticle] }}$ 
6. Lilford RJ, Mohammed MA, Braunholtz D, Hofer TP. The measurement of active errors: methodological issues. Qual Saf Health Care. 2003;12(Suppl II).ii8-12.[Full Article]

7. Shah JN, Maharjan SB, Manandhar K, Paudyal S, Shrestha $\mathrm{S}$, Shah S, et al. Early feeding and discontinuation of intravenous fluid after laparoscopic cholecystectomy. J Nepal Health Res Counc. 2012;10(20):28-31.[PubMed]

8. Shah JN, Maharjan SB, Paudyal S. Routine use of antibiotic prophylaxis in a low-risk laparoscopic cholecystectomy is unnecessary: a randomized clinical trial. Asian J Surg. 2012;35:136-9.[PubMed]

9. Lyons JM 3rd, Martinez JA, O’Leary JP. Medical malpractice matters: medical record M \& Ms. J Surg Educ. 2009;66(2):113-7.[PubMed]

10. Shah JN, Pokhrel Y, Hassan K, Thapa G, ManandharK, Maharjan SB. Is routine hospital visit after day case inguinal hernia surgery in children necessary? J Nepal Health Res Counc. 2013;11(23):35-9.[PubMed]

11. Ministry of Health and Medical Education of Iran MOHME: Quality of Medical Records. 2000. Document 620
12. Ehsanullah J, Ahmad U, Solanki K, Healy J,Kadoglou N. The surgical admissions proforma: Does it make a difference?Ann Med Surg. 2015;4:53-7. [PMC free article]

13. Faraj AA, Brewer OD, Afinowi R. The value of an admissions proforma for elderly patients with trauma. Injury. 2011;42(2):171-2.[PubMed]

14. Diver AJ, Craig BF. Admission proforma significantly improves the medical record. Scott Med J. 2005;50(3):1012.[PubMed]

15. O'Driscoll BR, Al-Nuaimi D. Medical admission records can be improved by the use of a structured proforma. Clin Med. 2003;3(4):385-6.[PubMed] 